\title{
DESALINATION AND BOREHOLE CONSTRUCTION FOR ABSTRACTION OF SALINE WATER AND CHANNELING BRINE DISPOSAL
}

\author{
Sampatakakis P. ${ }^{1}$, Manthos G. ${ }^{2}$ and Kepas A. ${ }^{3}$ \\ ${ }^{I}(P h D)$ Hydrogeologist -Institute of Geology and Mineral Exploration, ${ }^{\text {st }}$ Spirou Louis St., Olympic \\ Village, 13677, Acharnae, Greece, sabatakakis@igme.gr,tel 2131337400 \\ ${ }^{2}(M S c)$ Surveyor Engineer - Institute of Geology and Mineral Exploration, ${ }^{\text {st }}$ Spirou Louis St., \\ Olympic Village, 13677, Acharnae, Greece, gmanthos007@hotmail.com, tel.6972620947 \\ ${ }^{3}(\mathrm{MSc})$ Environmentalist - Institute of Geology and Mineral Exploration, ${ }^{\text {st }}$ Spirou Louis St., \\ Olympic Village, 13677, Acharnae, Greece, alexkepas@hotmail.com, tel 6939317216
}

\begin{abstract}
The purpose of this research is to present all the technical details, but also the scientific criteria according to which there is the possibility to make a borehole for the extraction of the saline water and channeling of brine in another borehole. This methodology has purpose to prove that this way of extraction of saline water (or sea water) through the borehole and the channeling of the remain into another one has multiple assets comparing to the classical method of the direct extraction and return of the residue into the sea. These assets are considered to be better because of the extraction which may be in the inland, hypsometrically more advantageous. Also, the channeling of the brine disposal in a nearby borehole is safer from an environmental point of view because it does not disturb the flora and fauna in the benthic zone of the marine space, but also a less expensive solution than channeling it straight into the sea. In any case, it is a necessary presumption that the hydrogeologic conditions in the area where the work is taking place to ensure a high factor of permeability and hydraulic connection with the sea area. The application of this technique was completed with some success in the case of Agistri Island (and homonymous municipality) which is located in the Saronic Gulf, southwest of Salamis Island. Although the distance between the two boreholes should be larger in order to prevent the risk of dynamic input of brine disposal to the borehole extraction because of the radius of influence, which would destroy the osmosis membranes. After the appropriate evaluation of the test pumping elements, this was ensured by placing the appropriate sensors of salinity.
\end{abstract}

Keywords: Pumping Boreholes Radius of Influence, Osmosis Membranes, Desalination Technique.

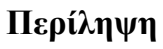

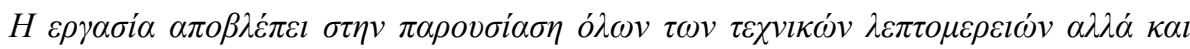

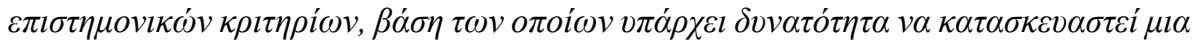

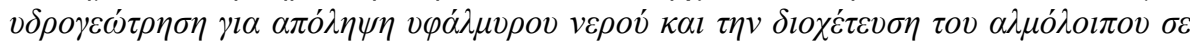

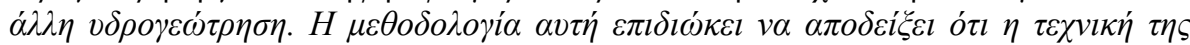

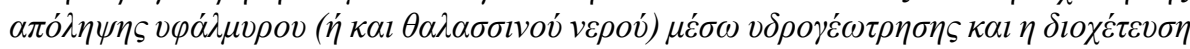

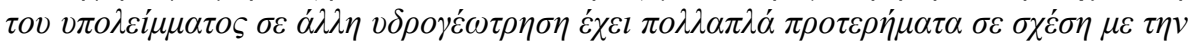




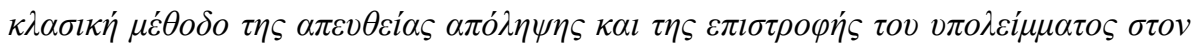

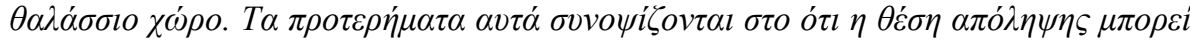

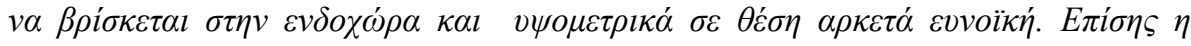

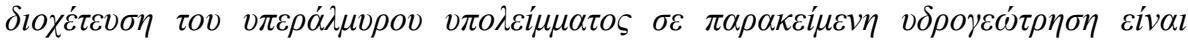

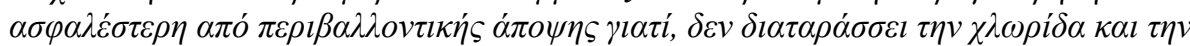

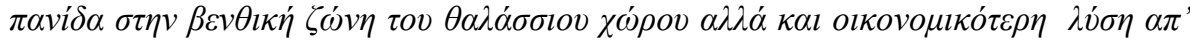

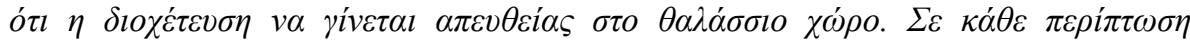

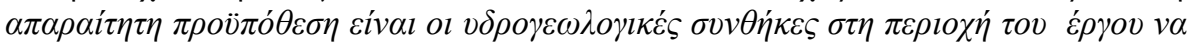

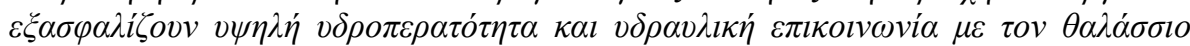

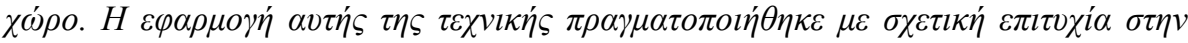

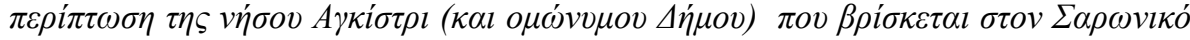

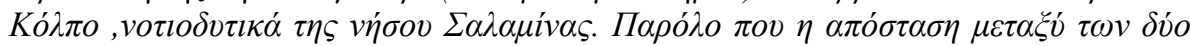

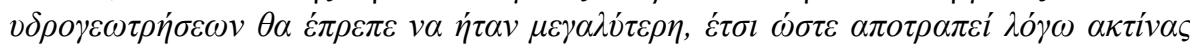

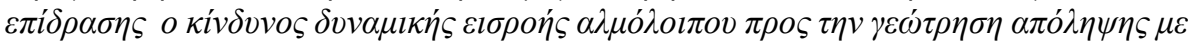

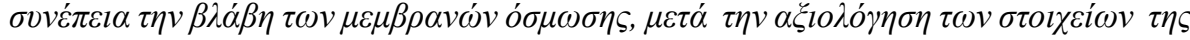

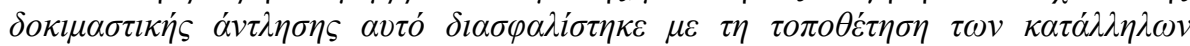
$\alpha \iota \sigma \theta \eta \tau \dot{\rho} \rho \omega \nu \alpha \lambda \alpha \tau o ́ \tau \eta \tau \alpha \varsigma$.

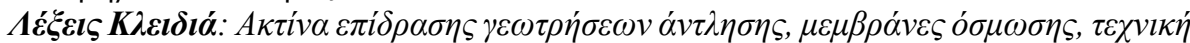
$\alpha \varphi \alpha \lambda \alpha ́ \tau \omega \sigma \eta \varsigma$.

\section{Introduction}

Brine disposal at sea is the subject of ongoing research particularly in large desalination plants because of the impact on flora and fauna. The flow through a bundle is considered to be a significant factor in terms of hydraulic and hydrochemical in combination with the mobility of the sea water and the morphology of the seabed in every case.

The research, this paper refers to, was carried out in 2013-2014 in order to solve the problem of the water needs of Agistri municipality, which up to that time were covered by water transport ships with more than triple cost. In the area of desalination plants two (2) boreholes (one spare in case of need) were constructed for the abstraction of saline water. The "host" borehole, where the brine disposal would be channeled, was built in the east side $353 \mathrm{~m}$ away from the spare one. The technical specifications and the hydrogeological environment, where the boreholes were built, were determined in details according to the technical report of IGME (Fotiadis, Sabatakakis and Stefouli, 2010, Library IGME).

Because the municipality had no other private property in the area where desalination plants would be built, borehole operations were necessarily executed at predetermined positions regardless of the radius of influence of borehole extraction. That was the reason, the relevant pumping test was done to determine precisely the radius of influence.

The work of pumping test was held on 03.07.2014 under the supervision of the technical unit of IGME, technical support from the Manufacture Company and technicians of the municipality. The collected data from these operations are presented in the following chapters and conclusions.

\section{Topography Info}

Agistri Island belongs to the Region of Attica and geographically is one of the Saronic Gulf islands, which is included in the topographic sheet "AGKISTRION" (Fig. 1).

The total area of the island is 11.8 square kilometers. The locations of boreholes which were constructed are shown in the orthophotomap extract of the NATIONAL CADASTRE bellow (Fig. 2). 


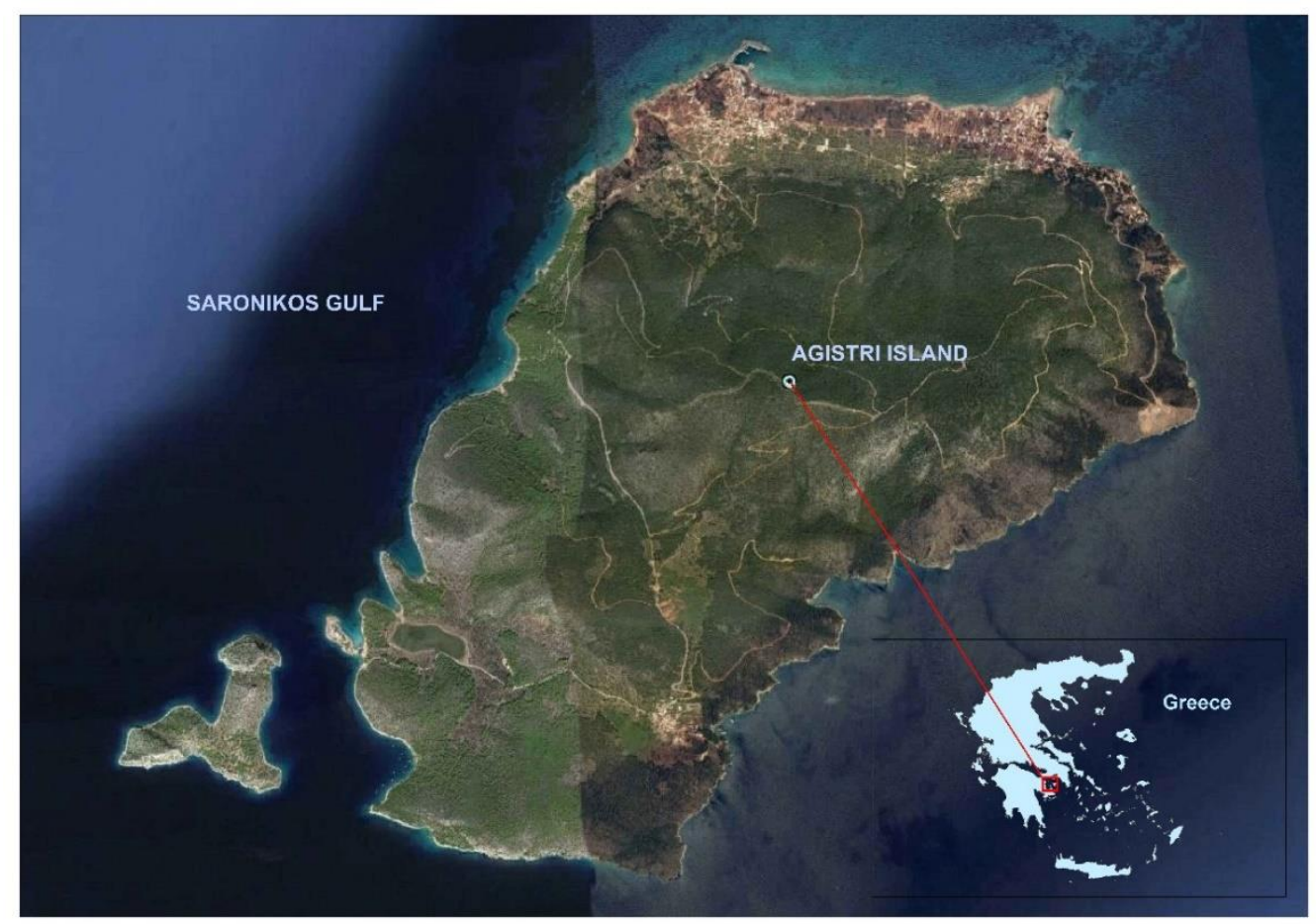

Figure1 - Satellite Image of Agistri island.

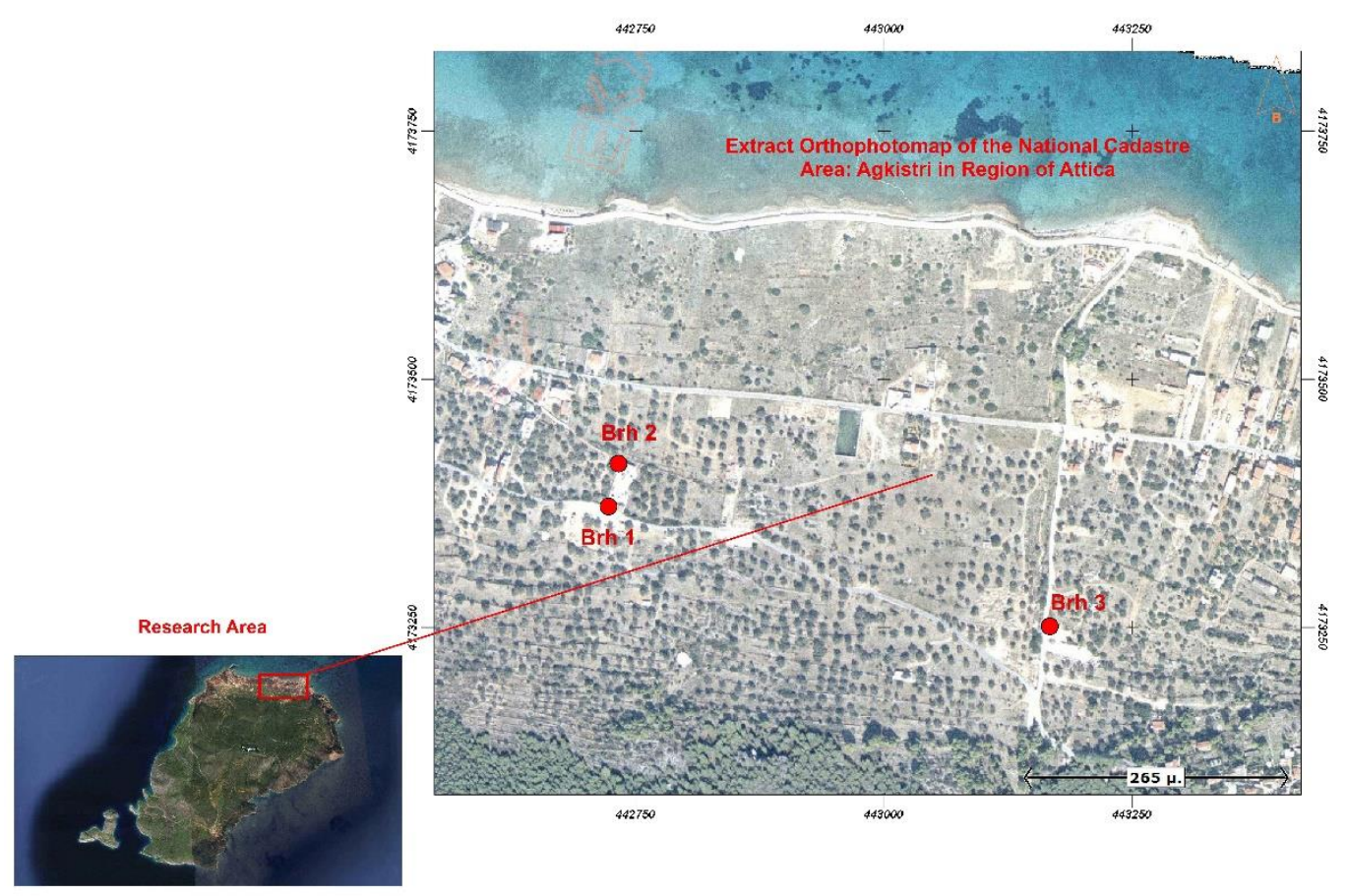

Figure 2 - Research area. 
In the recreation area, two boreholes were constructed for extraction with the purpose one of them to act as a backup.

The distance between the two pumping drillings is $19 \mathrm{~m}$.

The position of the "host" borehole for the discharge of brine disposal (Brh3), was constructed on a site east of these two boreholes, specifically near the bed stream. The distance between Brh3 and the positions of boreholes Brh1 and Brh2 is approximately 353m (field measurement).

Table 1 - Coordinates of Boreholes.

\begin{tabular}{|lccl|}
\hline ID & \multicolumn{1}{c}{ X } & Y & USE \\
\hline Brh3 & 443164,807491 & 4173253,744265 & Host Borehole \\
\hline Brh 1 & 442724,672943 & 4173378,789831 & Borehole Extraction \\
\hline Brh 2 & 442732,712088 & 4173413,626123 & Borehole Extraction \\
\hline
\end{tabular}

\section{Geological Conditions}

Based on geological mapping carried out under the IGME (Fotiadis, 2010) which is included in the Geological Map Sheet “AGKISTRION" (ver. IGME). The area of Agistri island belongs Tectonicstratigraphically to the Tectonic zone of Sub-Pelagonian zone, spreading from NW to SE and structured by the Greek mountain ranges and structured consecutively by Triassic-Jurassic to Doggerium age medium bedded to thin bedded carbonate rocks (Fig. 3). The stratigraphic thickness of these formations is estimated between 250 to $500 \mathrm{~m}$. (approximately). The tectonic structures of tectonic horsts which form the morphology of the island is characterized by two main tensile systems of tectonic streak:

- With a main tensile N-S direction forming faults directed to the east-west side (newer age)

- An older tensile phase with direction N-NE / S-SW, forming faults directed N-NW / S-SE. These normal faults with a visible jump where in some areas of the island are more than 150 $\mathrm{m}$ (based on field observations). Around the coastal zone, especially in the northern part of the island, marine formations of Neogene, Pleistocene and alluvial deposits of limited thickness are respectively developed, which derive from scree and debris and small talus cones as well.

On the site where desalination plants and the two boreholes extraction exist, geological conditions are formed by Quaternary deposits. On the other hand, geological conditions at the site where drilling has been made for brine disposal through the desalination process are identified by the appearance of the Trinity - Jurassic limestones.

The thickness of Neogene and Pleistocene formations in the area of Brh2 and Brh3 pumping drillings was precisely determined from the data obtained during the perforation.

Particularly in Brh1, the thickness of Holocene and Pleistocene deposits was determined at $38 \mathrm{~m}$. These deposits consist of conglomerates, mixed materials of sand-clay-gravel and alternations of conglomerate intercalations slightly consolidated. The Neogene materials whose depth was drilled from 38 to $75 \mathrm{~m}$., are consisted of alternating sands and sandy-marls. The carbonate rocks (limestones bedded), were found deeper than $75 \mathrm{~m}$ and up to $105 \mathrm{~m}$, where the perforation stoped. They are fractured and sometimes karstified.

The stratigraphic column of Brh2 perforation, consisting of the following:

0-32 m. from Pleistocene deposits,

$32-60 \mathrm{~m}$. from Neogene materials 
60-104 m. from fractured limestone and karstified.

In Brh3 borehole drilled entirely limestones from the surface of the ground up to 100 meters depth.

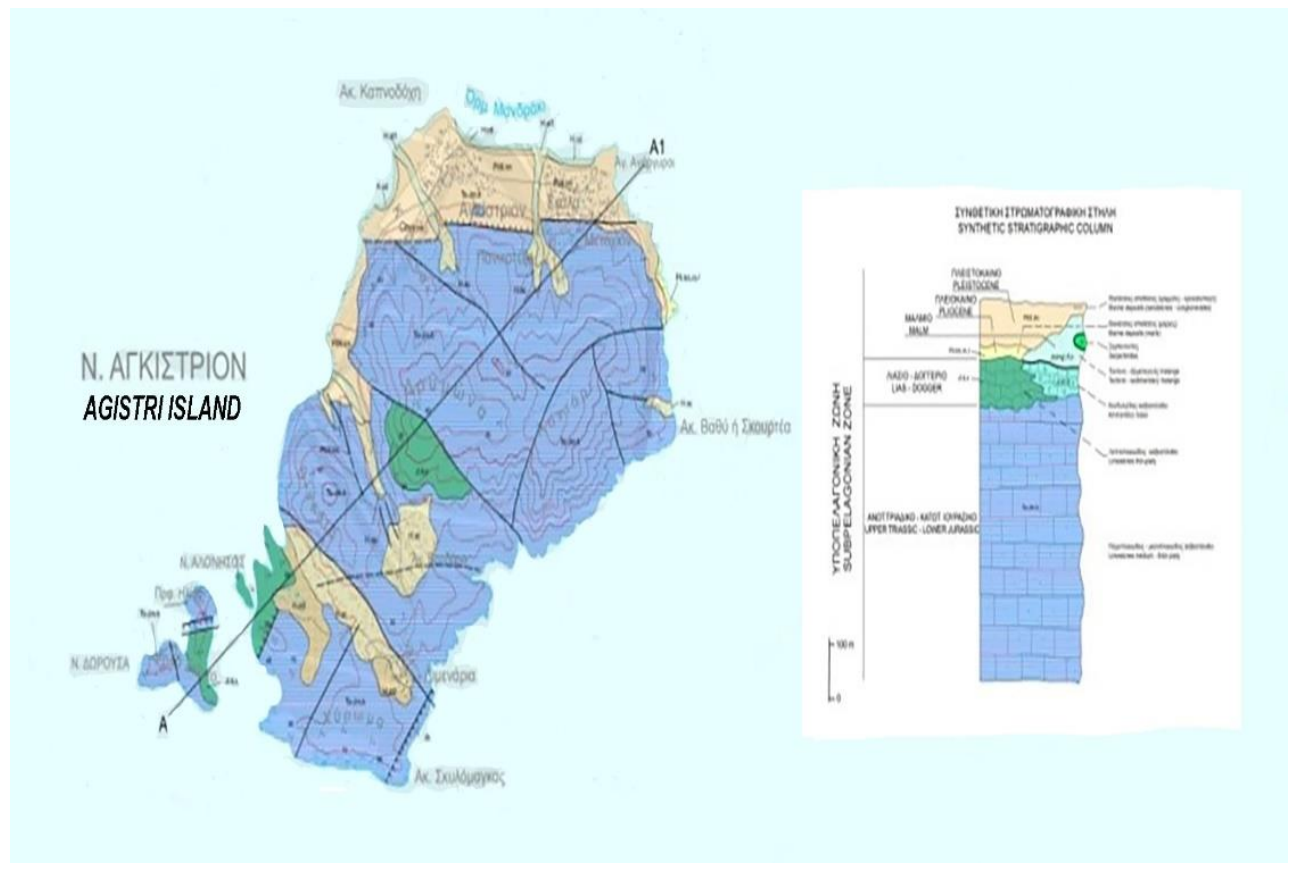

Figure 3 - Geological Map of Agistri Island.

\section{Aquifer Features}

Taking into account the dense pine vegetation that covers the area of Agistri island, which further enhance the infiltration of rainwater, as well as the stream flows which exist in the area do not indicate steady or periodic runoff, but only occasional one after heavy rainfall and this is partly due to the small extent of the basin and the other to the high permeability of carbonate formations that is structured throughout the island.

At a short distance away and west of the site which has been chosen for the position of host borehole (C3), pass through the stream flow bed "Skala" (Fig. 4). In that bed, no runoff occurs, either steadily or periodically throughout the year, but only after intense rainfall (based on information given by the municipality). Along the side of this stream flow bed, there is a natural restoration and there haven't been done any artificial works.

The geological conditions of the island, as mentioned above, are determined by the dominant carbonate formations spread throughout the island, except for the coastal zone, where in some areas thick Quaternary but limited deposits are identified.

Because of the high permeability of carbonate formations and their thickness, which allows them to grow deeper from the sea level in all areas of the island, the hydrogeological conditions were assessed to be negative. As a result, the underground aquifer will be brackish throughout the island (Fig. 6). 


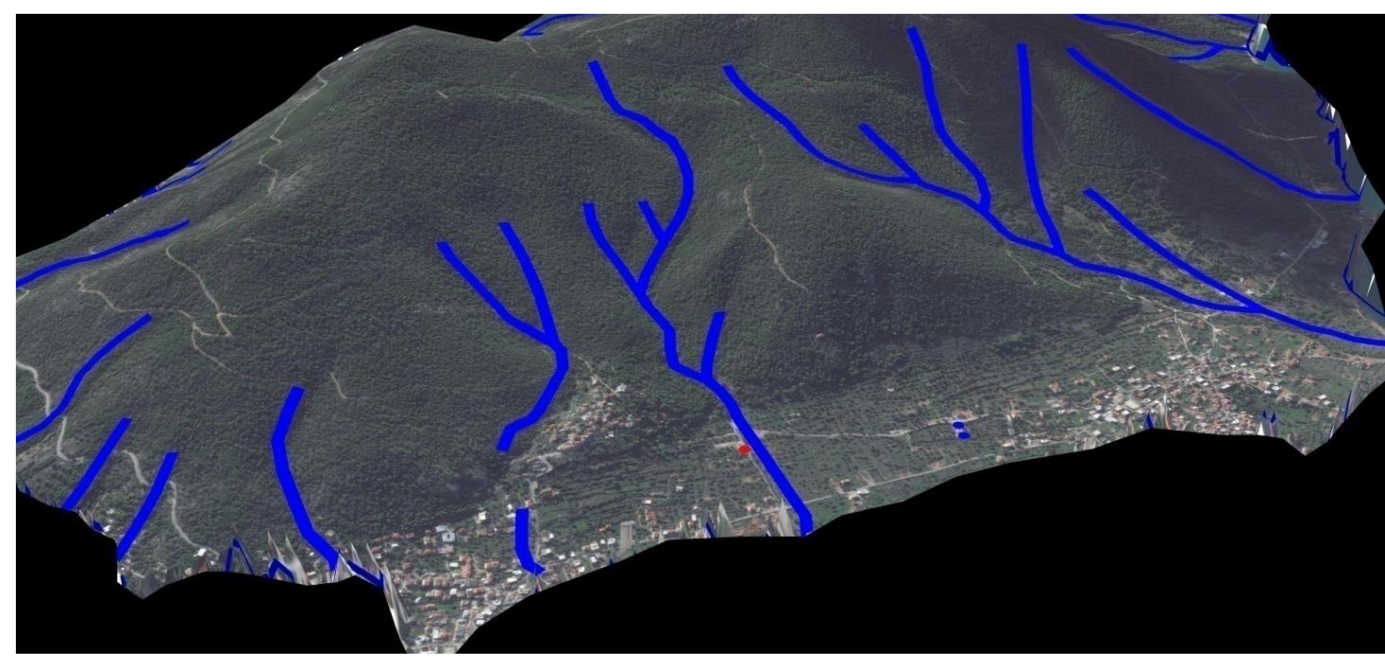

Figure 4 - Three dimensional representation of Borehole construction.

The major coastal discharges, based on satellite analysis which was presented earlier, are found mainly in the south and east coast. This suggests that the bulk of brackish aquifer drains to the mentioned coastline (fig. 5)

The limited Quaternary deposits, particularly in the area of interest, where the spreading is the most important of any other part of the island, are capable of forming a very shallow but limited aquifer supply, which was used in the past for water pumping and irrigation.

The two boreholes, which will be used for the abstraction of seawater, will be drilled to a depth multiple of thick Quaternary deposits, in order to identify the carbonate formations (Fig. 6). The depth of both perforations is expected to detect underground water equivalent to the hydrochemical composition of the sea water. The technical specifications of these drillings and hydraulic relation with both the hydrogeological and marine environment are described in the next chapter.

The water that is pumped from the two boreholes (Brh1 and Brh2) is almost sea water that comes from the intense brackish karstic limestone aquifer and is mixed with a very small amount of fresh water which comes from the limited capacity of granular aquifer formations.

\section{Test Pumping}

The ground water level at (3) boreholes was measured and calculated to be the same as the sea level. In relation to the topographical height of each post the depth level was estimated to $19.68 \mathrm{~m}, 18,33 \mathrm{~m}$. 32.05 respectively on Brh1, Brh2, Brh3. The pumping duration in summer is continuous. From the beginning of the operation until now there has not been noticed any increase of salinity in the pumped water from the two boreholes (Brh1 and Brh2). This fact is controlled by an automatic monitoring system that measures the conductivity and the pressure in the osmosis membranes. This system ensures safety so that any complications will be prevented from the increase of salinity. This event might cause the capture of hypersaline water because of the radius of influence, which will be spread to the place where brine disposal will be channeled through a closed pipe at the position of Brh3, as it will be shown below. The procedures which were conducted, were a test pumping in Brh1 with constant flow (about $35 \mathrm{M} 3 / \mathrm{h}$ ) and monitoring of level changes in Brh3. The distance as mentioned above, between Brh1 - Brh2 is $19 \mathrm{~m}$ and the one between Brh1 - Brh3 is $352 \mathrm{~m}$. 

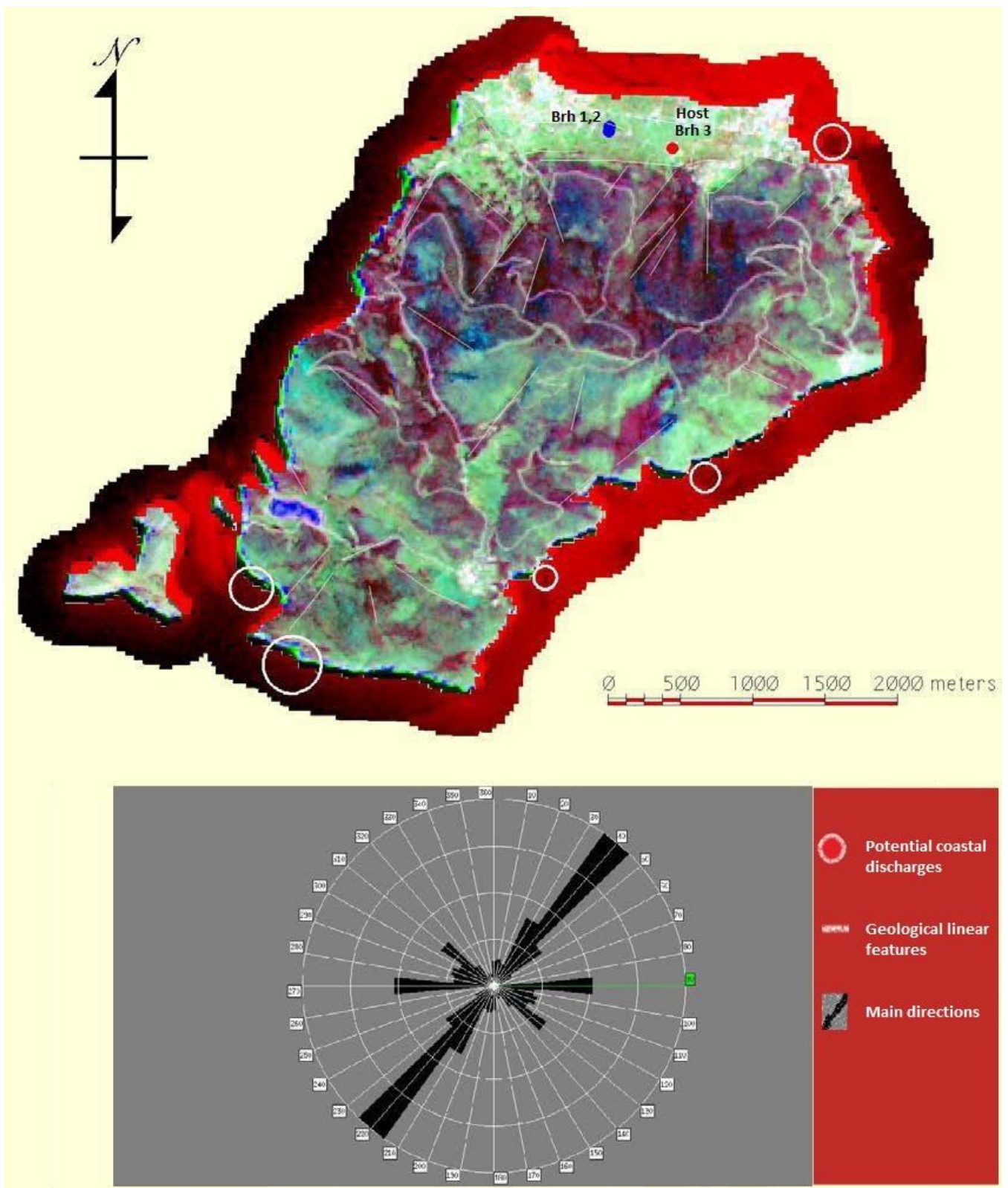

Figure 5 - Potential coastal discharges.

The altitude of Brh2 was approximately found one meter lower than that of Brh1.

The water extraction was taken from Brh1 with a constant flow of $35 \mathrm{~m} 3 / \mathrm{h}$ with simultaneous monitoring of the level changes in Brh1 and Brh3.

At non equilibrium flow conditions the THEIS equation can be applied.

$\mathbf{s}=\mathbf{Q} / \mathbf{n T} . \mathbf{W}(\mathbf{u})$ 
$N<2$

Schematic section of

Geomorphological landscape

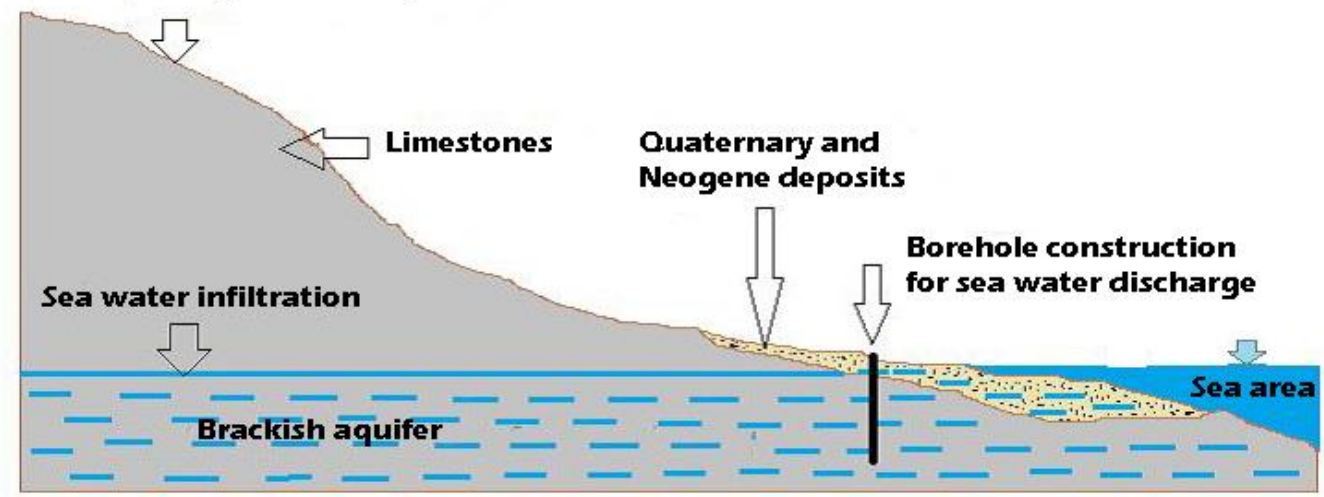

Figure 6 - Schematic hydrogeological section.

The result coming up from this mathematical formula is that the growth of the conical depression and the radius of influence is analogous of borehole discharge $(\mathrm{Q})$ and inversely analogous to the transmissivity (T).

Similarly in the case of steady flow in a confined aquifer, DUPUIT - THIEM can be applied:

$\mathrm{s} 1-\mathrm{s} 2=\mathrm{Q} 1 \mathrm{n}(\mathrm{r} 2 / \mathrm{r} 1) / 2 \pi \mathrm{T}$ and h22 $-\mathrm{h} 12=\mathrm{Q} 1 \mathrm{n}(\mathrm{r} 22 / \mathrm{r} 12) / \pi \mathrm{K}$.

In both cases of the test pumping, the stabilization was achieved within $75 \mathrm{~min}$.

The depth of the station where the water extraction was pumped from, was $36 \mathrm{~m}$ that is to say opposite to the blind pipes.

The monitoring of the level in both Boreholes Brh1 and Brh3 showed that the drawdown was about one (1) meter and $0.43 \mathrm{~m}$ respectively for a time period of 75 minutes, where it was stabilized. Changes in borehole 1 are shown in Figure 7.

To estimate the distance where the falling level in Borehole 3 is zero used two ways were used: the graphical resolution of the level drop (s) - distance (r) (Fig. 8) and the formula (Walton, 1970):

$\mathbf{R}=\mathbf{1 , 5} \sqrt{ }$ K. H. $\mathbf{t} /$ Pe.

For "K" and "Pe" figures were used the ones according to the Tables of US-PWRS (1981) and JOHNSON (1967) respectively. The "K" was set at $103 \mathrm{~m} /$ day and the figure of "Pe" at 0.1 . The "H" was determined based on the thickness of limestone which was perforated $30 \mathrm{~m}$. As far as the figure of " $t$ " was determined to $75 \mathrm{~min}$ (i.e. 1.25 hours). Solving the above equation shows that the $\mathrm{R}$ equals to $592 \mathrm{~m}$. From the graph (Fig. 8), the figure was determined to $625 \mathrm{~m}$. It means that the formula can be applied to the specific conditions. The small deviation is due to the fact that figures out of field measurements were introduced into the equation.

The figures above indicate that the host borehole Brh3 in which the brine disposal from desalination was channeled, has been drilled within the radius of influence. That fact was confirmed during the test pumping, where the level of Brh3 drop to $0,43 \mathrm{~m}$ lower. 


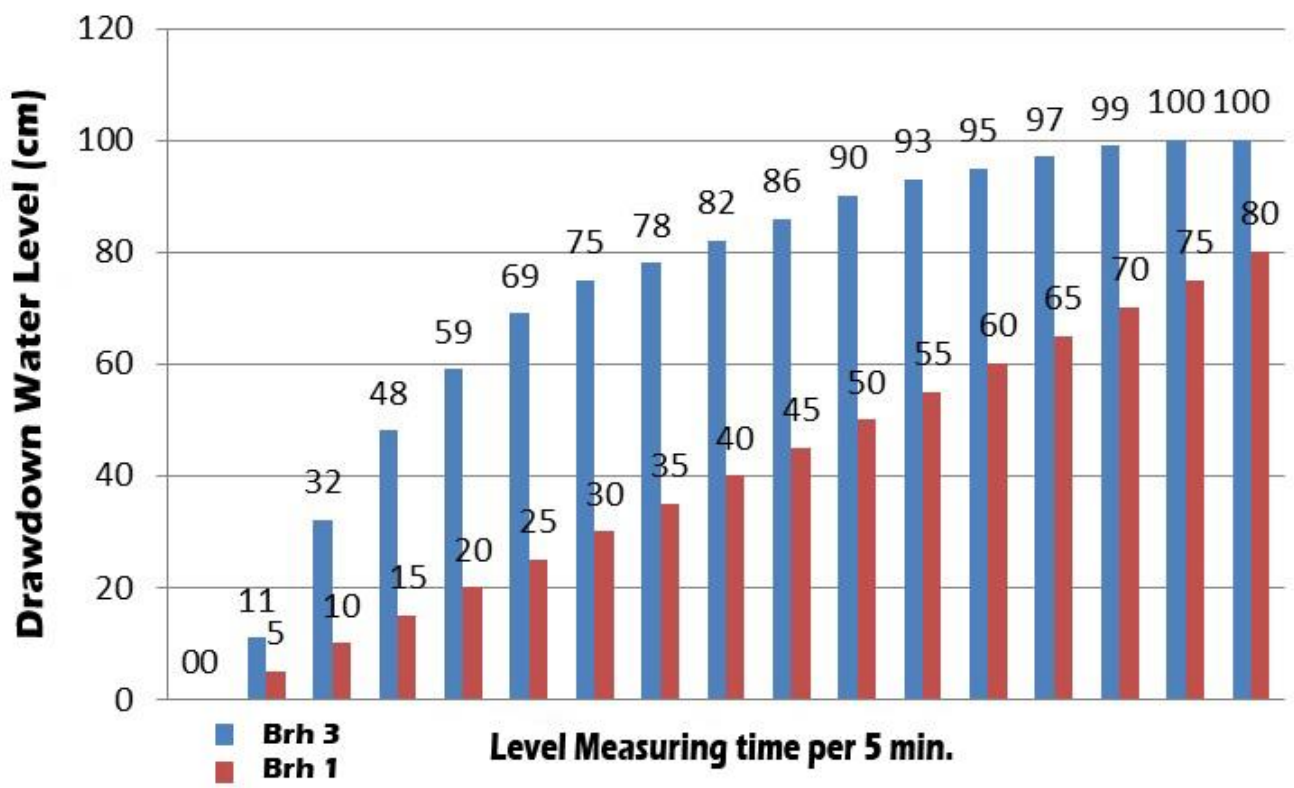

Figure 7 - Variance of water level at Boreholes.

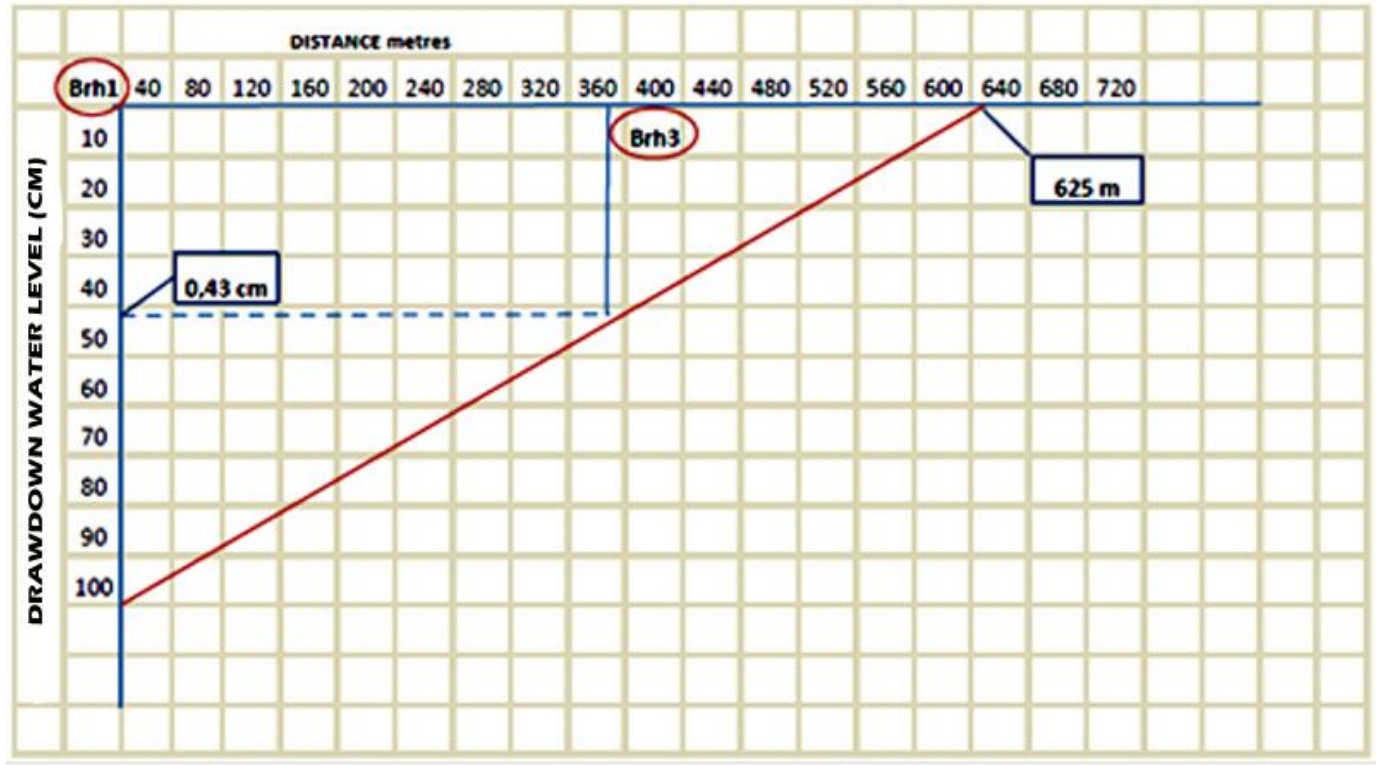

Figure 8 - Graphical analysis of the drawdown level.

\section{Dispersion of Brine Disposal}

Brine disposal is a major issue and is the subject of ongoing research. Nowadays, recipients under conditions are considered to be the followings: surface water, waste water disposal and biological treatment station, drilling, evaporation ponds, sink basins, maritime space (Who, 2007). The water flow jet outcome from the brine disposal is a complex hydraulic process. The high flow rate of the kinetic energy, which gradually is lost due to the contact with the sea water, is the factor which produces the desired dissolution of the brine (Alberston et al., 1950). The buoyancy force, the 
opposing force of gravity due to increased weight of the brine as well as the characteristics of the impulse and the outflow geometry affect the water flow in the near zone (Tsanis and Valeo, 1994). Whereas, stratification and horizontal movements dominate in the intermediate zone (Akar and Jircan, 1991), in contrast to the near vertical mixing zone. In case of channeling into drilling as in Agistri, where the recipient of the brine disposal is seawater, but this is an almost static hydrostatic surface and mobility conditions of sea currents do not apply. So the cast of the brine and the accumulation will follow the conditions shown in the intermediate zone described above. These hydraulic conditions will also affect the speed of hydrochemical mixing of the brine with seawater which is expected to be slower. In such cases, there should be constructed an observation borehole in the intermediate distance between drilling and deliverability drilling rejection.

As far as the dispersion of the brine disposal which is taken from the desalination and then channeled into Brh3, taking into account the hydro-lithological conditions under which the water is channeling, it is important to stress the following remarks:

a) The process of "dispersion" is an unstable, irreversible mixing process, since the injected brine disposal (pipeline approx. 74,000 $\mathrm{mS} \mathrm{/} \mathrm{cm)} \mathrm{will} \mathrm{be} \mathrm{dispersed} \mathrm{into} \mathrm{the} \mathrm{water} \mathrm{(sea).}$

b) The channeling of the residue into a hydrogeological formation (limestone), which may be considered as a "homogeneous" material for the scale of the project.

c) The borehole Brh3 is the destination of the residue by desalination, which is chemically can be mixed with seawater.

d) The level of the seawater at the position where Brh3 is located is about $32 \mathrm{~m}$. deep (it was determined at $32.05 \mathrm{~m}$. during the test pumping).

e) The dispersion process takes place in conditions of "free aquifer". In this case, as it is known, the dispersion is proportional to the transmissivity (T) and inversely proportional to the storage capacity, i.e.

$\boldsymbol{\alpha}=\mathbf{T} / \mathbf{S y}$.

In the place where the Brh3 has been constructed, as mentioned above, limestones predominate. But in case, they are considered as a homogenous material, as mentioned above, then the dispersion as to the hydrostatic surface (two-dimensional dispersion) should take the form of almost concentric circles. Considering all elements of research, it was not possible to determine at what distance from the injection point (Brh3), occurs complete mixing. For this detection required further observation points (boreholes). Obviously, the same applies to the lateral dispersion.

\section{Conclusions}

The abstraction of brackish or seawater through a borehole aiming to the desalination in coastal karst areas which have "an open" hydraulic connection with the sea and also the channeling of brine into a borehole which is in the same geological formations, is a better solution and perhaps more economical and safer from an environmental point of view than the direct channeling into the sea area. And that's because it is possible the water extraction and channeling to be done 'in situ" of the process facilities. Therefore, the construction of a large pipeline at a specific depth, where the brine will be channeled into the sea considering the existence of shallow waters, especially in the Northern part of the island, will be avoided. In addition, the channeling of the brine in the host borehole will not be reason for further deterioration of underground water due to the existence of unusable brackish waters in the island. Similarly, in the case of the surface soil, where the brine channeled indirectly in the sea area through the limestones.

The distance of the host borehole has to be longer than the radius of influence so that the "capture" of brine disposal, which may cause damage to the osmosis membranes, will be prevented. Howeve $\mathrm{r}$, as far as the distance is concerned, apart from the radius of influence, the dispersion of brine, wh ich definitely increases even more the safety distance, should be taken into account. 


\section{References}

Akar, P.J. and Jirra, G.H., 1991. CORMIXZ, An Expert System for Hydrodynamic Mixing Zone Analysis of Conventional and Toxic Multiport Diffuser Dischargers, EPA/600/3-91/073 U.S. Environmental Protection Agency, Athens.

Albertson, M.C., Dai, Y.B., Jensen, R.A. and Rouse, 1950. Diffusion of Submerged Jets, Trams, ASCE., 115, 639-697.

Fotiadis, A., 2010. Geological map of "Agistri Island” scale 1:50.000, IGME.

Fotiadis, A., Sampatakakis, P. and Stefouli, M., 2010. Hydrological conditions and technical specifications for desalination and borehole construction in the area of Agistri island, Technical report of Central library of IGME.

Johnson, A., 1967. Specific yield -compilation of specific yields for various materials, U.S., Geological Survey Water Supply Paper, 1662 -D.74 pp.

Theis, C.V., 1935. The relation between the lowering of the piezometric surface and the rate and duration of discharge of a well using ground-water storage, Trans. Amer. Geophysical Union, $16,519-524$

Svensson, M., 2005. Desalination and the Environment: Options and consider rations for brine disposal in inland and coastal locations.

U.S.- Water and Power Resources Service., 1981. Groundwater Manual, 480 pp.

Walton, W.C., 1970. Comprehensive analysis of water -table aquifer test data, Ground Water, 16, 311-317.

Who, 2007. Desalination for safe water supply. Guidance for health and environmental aspects applicable to desalination, Public health and environment, Geneva 2007. 